\title{
Ethical principles
}

SADJ June 2019, Vol. 74 No. 5 p260 - p261

WG Evans

Ethical principles are the absolute central core to ensuring sound professional practice by the health care teams. Over the multiple years of the evolution of these professions, those principles have been honed and polished, the objective being to ensure absolute clarity for the understanding of those obligated to observe the directives. The American Dental Association have identified five fundamental principles which form the foundation of the ADA Code of Ethics. The Health Professions Council of South Africa have devolved the principles into thirteen "core values."

Whilst it may have been the health professions which first recognised the need to formalise the ethics of practice, considerable philosophical thought has been focussed on ethics in society as a whole. We can evoke Aristotle and Plato, Augustine and Aquinas, Kant and Daniels... as were eloquently scrutinised in the Ethics article published in the SADJ in April this year. Indeed the year has seen a series of events across several countries in which ethics should have played a most dominant role... the election of representatives to govern the people... whether in Africa, the United States or Turkey, the Principles of Ethics should have been paramount.

An intriguing article appeared on the Web in 2016... "The Five Principles of Integrity in Elections." How does society evaluate ethics on these events, so vital to the progress of the country? It has of course been observed that a democracy is really free only on Election Day! If that is true how much more essential that election ethics are impeccable. The five Elements were defined as:

\section{Independence \\ 2. Transparency \\ 3. Integrity \\ 4. Competence \\ 5. Fairness}

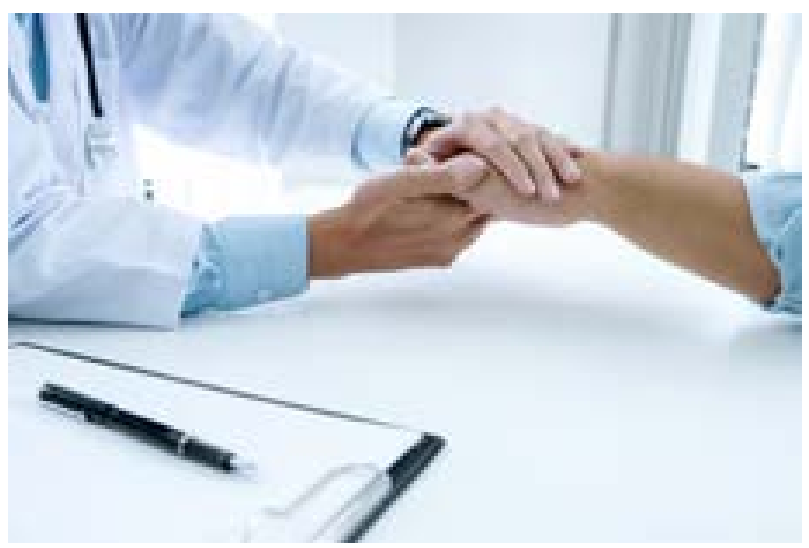

WG Evans: Managing editor, Email: bill.evans@wits.ac.za
But hark.. these elements are designed to apply to the Election Officials, who must show independence, be open to inspection, be eminently trustworthy, demonstrate efficiency and be fair.

These are surely characteristics that also mark the ethical professional. How does the ADA describe this individual? The five fundamental ADA principles are patient autonomy, non-maleficence, beneficence, justice and veracity. Can we link the ADA principles with the elements describing ideal election officialdom?

Justice and veracity are integrity and transparency, patient autonomy could be linked to independence, non-maleficence and beneficence relate to competence and fairness.

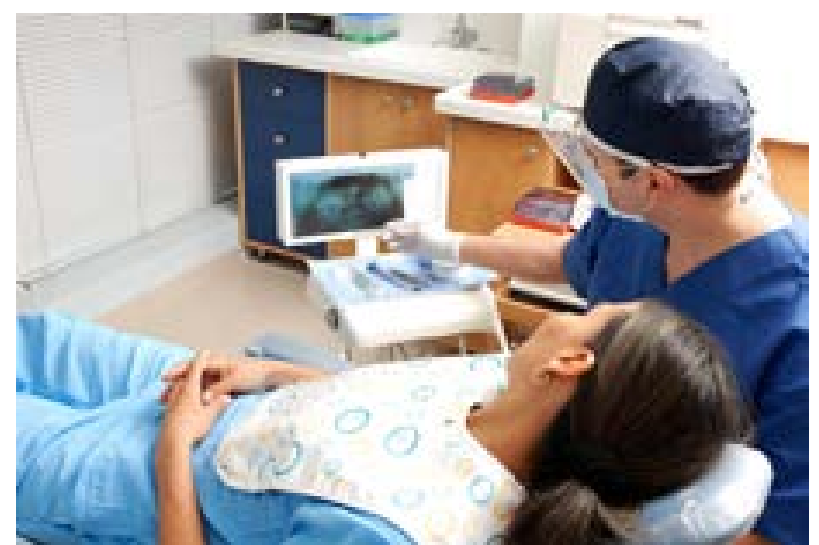

The five elements of Election Integrity combined with the five fundamental ADA principles should accommodate the thirteen core values enunciated by the HPCSA. Those thirteen core values with corresponding Elements and Principles are listed on p209.

It may be seen that there is considerable overlap.

The HPCSA Core Values spell out our commitments more completely (to ensure absolute clarity!).

There are social and civil privileges which are basic to the tenet of free and fair elections... such as the freedom of speech, the freedom of association and the freedom of assembly. An ethical society provides those privileges without demur. Dental professionals hope to live in such an ethical society... but the aspirations are for a society in which they may be also held in considerable esteem. Earning that privileged position imposes an obligation for those in the profession to uphold high levels of ethical conduct... to be upheld at all times... without regard for whether it is election time or not.

\section{References}

https://www.governing.com/gov-institute/voices/col-5-principles-integrity-election-administration.html 